Portland State University

PDXScholar

\title{
Do Sarcastic Exchanges with Millennial Employees Influence Performance Appraisal Effectiveness?
}

Karissa Burright

Portland State University

Follow this and additional works at: https://pdxscholar.library.pdx.edu/honorstheses

Let us know how access to this document benefits you.

\section{Recommended Citation}

Burright, Karissa, "Do Sarcastic Exchanges with Millennial Employees Influence Performance Appraisal Effectiveness?" (2017). University Honors Theses. Paper 368.

https://doi.org/10.15760/honors.361

This Thesis is brought to you for free and open access. It has been accepted for inclusion in University Honors Theses by an authorized administrator of PDXScholar. Please contact us if we can make this document more accessible: pdxscholar@pdx.edu. 
Do Sarcastic Exchanges with Millennial Employees

Influence Performance Appraisal Effectiveness?

by

\title{
Karissa Burright
}

An undergraduate honors thesis submitted in partial fulfillment of the

\author{
requirements for the degree of \\ Bachelor of Science \\ in \\ University Honors \\ and \\ Business Administration: \\ Management \& Leadership \\ and \\ Human Resources Management
}

Thesis Adviser

Dr. Isaac Dixon

Portland State University 


\begin{abstract}
This literature review explores the intricacies of sarcasm in the supervisor-employee relationship; particularly, it looks at sarcasm between supervisors and Millennial generation employees and possible ways it influences performance appraisal effectiveness. It focuses on five key intersections, as follows: sarcasm, trust, Leader-Member Exchange (LMX), performance appraisals, and the Millennial generation. The purpose is to identify and define these intersections, their implications, and the gaps in current research. Thus far, there is little research on these intersections, requiring this paper to link the overlapping areas between subjects. Therefore, this research builds upon the work or psychologists, sociologists, human resources management, and other fields for an interdisciplinary review. The findings show that it is likely for sarcasm between a supervisor and their Millennial employee to have a negative impact on the relationship, damaging trust and creating obstacles for performance appraisal effectiveness. However, there are many benefits to sarcasm in the workplace, as well as evidence of sarcasm benefiting trust in relationships, calling for this subject to further be explored.
\end{abstract}




\section{Do Sarcastic Exchanges with Millennial Employees \\ Influence Performance Appraisal Effectiveness?}

Workplace dynamics have been a recognizable force for many years, but a certain trend that has been receiving more attention is the use of sarcasm. The use of sarcasm and irony is not new by any means; however, the Millennial generation, typically considered those born between 1980 and 1995, is particularly notorious for its use of self-deprecating humor and irony (Stewart, Oliver, Cravens, \& Oishi, 2016). Millennials are also ill-famed for being the young people that managers dread. They are an enigma of social media, entitlement, and technology that confound their older supervisors, and thus require different methods to successfully develop into competent and satisfied employees (Tulgan, 2009; Espinoza, Ukleja, \& Rusch, 2010; Stewart et al., 2016). Stewart et al. revealed that when researchers asked people from multiple generations what made their generation distinct, Millennials were the only generation to not have "work ethic" within the top five answers and the only generation to have "clothes" within the top five (2016). Generational differences are known to throw a curveball at management, but Millennials are an entirely new ballgame. Little research is available on how sarcasm in the workplace affects employee performance. The complexity of irony in different company cultures and the various contexts of irony in linguistics make it difficult to study, and even more so for Millennials rather than the general workforce. For the purposes of this literature review, I will be focusing specifically on the supervisor-employee relationship in terms of performance appraisals for Millennials and discussing intersections and gaps from previous research.

This research question was inspired during an internship I had at a company that disallows any sarcasm whatsoever. This policy included not only the definition of sarcasm I am focusing on in this research, but also any use of language that was not literal. We were 
challenged by leadership to be intentionally honest and clear with our language in hopes that it would diminish conflict and make it more difficult for our interactions to be misunderstood or misconstrued. This paper is not seeking to dwell on whether or not its implementation in this setting was effective or ineffective; instead, it is focusing on whether or not the use of sarcasm between a supervisor and their Millennial employee influences the effectiveness of their performance appraisals.

\section{Background}

Performance appraisals, often implemented as annual written evaluations of an employee, have been a key piece of the supervisor-employee relationship, requiring a sensitive balance between being frank and respecting an employee's integrity (Conant, 1973). Although appraisals are an essential part of employee development, improper implementation leaves many managers feeling that they have wasted their time and even caused irreparable damage to their relationships with their subordinates (Lawler, Benson, \& McDermott, 2012). The same study suggests that the actions and integrity of senior management, in addition to their performance management system, determine performance appraisal effectiveness; managerial input is significant, so performance appraisals should not be one-sided. It is important to acknowledge that although performance management systems are thoroughly researched, their proper implementation may still be limited in many business environments due to antiquated practices or lack of contextual understanding (Haines \& St-Onge, 2011). According to a study performed in 2011, only three in ten employees believe that their performance was actually increased by their company's performance management systems (Aguinis, Joo, \& Gottfredson, 2011). However ineffectively used, performance appraisals are not going away, as they are "vital to effective talent managing" (Lawler et al., 2012, p.191). 
Many famous writers, such as William Shakespeare and Oscar Wilde, have employed sarcasm and irony as a strategy of choice that is still relevant with today's youth. Although researchers continue to expand their work, little is known still of the cognitive and interpersonal consequences (Huang, Gino, \& Galinsky, 2015). I will be using existing research to substantiate that, to date, there is no concrete data solidifying either a net-negative or net-positive effect. Because there is inconsistency in the data regarding the guaranteed effects of sarcasm in the workplace, I will discuss both the possibility of positive effects and of negative effects.

This thesis will narrow in on the effects of workplace sarcasm on performance appraisals for Millennials. Millennials are highly relational creatures, seeking personal involvement from their supervisors beyond just knowing each other's names (Tulgan, 2009). This fact alone bolsters the necessity of positive relationships between supervisors and Millennial employees for effective performance appraisals. Tulgan also refers to the tactic of "loco parentis", meaning managers who are most effective in working with Millennials are those who act similarly to a Millennial's parent; this means being highly involved and integrated into the employee's work life. This parental effect also highlights that the relational dynamic will be different than in past generations, and therefore the effects of sarcasm in relationships could likely be different. For older generations, a supervisor may have been kept at a distance or treated like a peer, but with Millennials, they are more like family. Generational lines are often blurry, so in the case of this paper the Millennial generation will be defined as born between 1980 and 1995, as defined by the United States Census Bureau (Stewart et al., 2016). Research done outside of those parameters will be noted upon reference. 


\section{Methodology}

To recognize the terminology and intersections of research of an underrepresented subject, a literature review is necessary. No existing research addresses sarcasm, Millennials, and performance appraisals in union, so I have synthesized a composition of the current state of the average workplace to call attention to the opportunities for additional study. All articles represented in this review revealed significant findings about at least one of those three subjects. It is important to note that the variety of depth of research on each of these subjects is quite different, and that research on Millennials is recent and still in progress.

In accompaniment with peer reviewed journal articles, I chose two famous texts dedicated to supervising Generation Y. The first and perhaps most well-known is Managing the Millennials: Discover the Core Competencies for Managing Today's Work Force by Chip Espinoza, et al., and the second is Bruce Tuglan's Not Everyone Gets a Trophy: How to Manage Millennials $(2010 ; 2009)$. Both texts thoroughly focus on the plight of the managers of Millennials and discuss in detail the ways to mitigate generational differences and maximize the proficiencies of these young employees.

Not every performance management article references sarcasm; not every sarcasm article references performance management or appraisals. The overlap between these two subjects is employee relations. As performance appraisal effectiveness is dependent on the relationship between supervisor and employee, this makes the relational impacts of sarcasm extremely relevant (Pichler et al., 2015). Therefore, this paper will rely on research on employee relations to make claims of possible effects of sarcasm in supervisor-employee relations. 


\section{Literature Review}

To properly delve into this subject, it is essential to define thoroughly the various terms and concepts used in current research. Although much research has been done on sarcasm, there is not research to date on the intersection of sarcasm between supervisors and Millennial employees and how it influences performance appraisal effectiveness. My purpose is to draw conclusions based on the current research as well as to recognize gaps and poorly investigated areas that could inspire future research. The next section will analyze different avenues that have been explored up to this point, followed by a discussion on the application of this information and notes on future research.

\section{Sarcasm}

For this paper, I will be focusing on a specific type of irony, defined as "the presentation of a negative message through the use of a statement that is, on face, positive" or in other words, "relies on language with a literal positive meaning to communicate a negative message" (Boylan \& Katz, 2012, p.188; Miron-Spektor, Efrat-Treister, Rafaeli, \& Schwarz-Cohen, 2011, p.1066). It is important to note, however, that there are multiple types of sarcasm that convey various messages and the results of such studies are still relevant to this work. Specifically, the research of Miron-Spektor et al. and Pexman and Olineck $(2011 ; 2010)$. Because context is so essential to sarcasm interpretation and employee relations are a significant factor, sarcasm somewhat outside of my scope can still be relevant to speculate possible impacts.

One example of this is a study on the effects of sarcastic anger, which is a method a manager or supervisor might use with an employee (Miron-Spektor et al., 2011). This study focused on the cognitive effects in employees after experiencing or witnessing sarcasm as an 
expression of anger from a customer. The results of the study found that employees' creative problem solving increased when customers expressed anger indirectly through sarcasm rather than directly expressed anger. The research uses the theory of prevention orientation, meaning that humans naturally seek security and avoid pain and conflict. It also brought to light that coworkers who witnessed the sarcastic interactions were influenced by them and called managers to have a keen eye for these interactions.

The complexity of verbal irony in itself can be a barrier to proper communication. A 2010 study tested to see if sarcastic compliments (saying, "You look awful," when someone is obviously well-dressed) have the same effects as sarcastic insults (saying, "You look great," when someone is obviously not looking their best) and comparing the results with multiple theories of irony (Pexman \& Olineck). The study found that ironic insults, being the more conventional forms of sarcasm, were more likely to be rated as highly sarcastic compared to ironic compliments. Perhaps the most interesting finding was that the ironic statement was found to dilute the effect of both direct compliments and insults. Sarcastic compliments were found to be more mocking and less polite than direct compliments, and sarcastic insults were found to be less aggressive than direct anger or insults.

Not only is the interpretation of sarcasm a factor in the workplace, but the emotional effects that occur due to sarcasm as well. A study on employee flourishing found that people who use sarcasm in a negative manner contribute to employee languishing (Fredrickson \& Losada, 2005). Although it was considered a negative factor, the study also noted, "Appropriate negativity is a critical ingredient within human flourishing that serves to maintain a grounded, negentropic system" (p.685). This observation raises an important question; if negativity is a 
necessity to some extent, is sarcasm the form of negativity that is most beneficial in the workplace, particularly between supervisors and employees?

More research is being done to try to identify the possible positive outcomes of sarcasm in the workplace. Huang, et al. argued that sarcasm improves creativity for all parties involved (2015). Huang, et al. notes that although many seem aware of the potential negative outcomes of using sarcasm in the workplace, that does little to dispel it. The findings of this research showed not only that sarcasm use increased creativity for both recipient and expresser, but also that there was an important relational factor that mediated positive or negative outcomes. This mediator was interpersonal trust. According to the article, interpersonal trust "helps reduce the relational cost of sarcasm for both parties but still allow organizations to take advantage of its creative benefits" (Huang, et al., 2015, p.162).

\section{Trust}

Interpersonal trust is the "willingness to accept vulnerability based on positive expectations of another's intentions or behavior" (Huang, et. al, 2015, p.164). Huang, et al. theorized that individuals who trust one another are likely to have a lower sense of conflict, particularly when the intentions are somewhat unclear. In simple terms, one is more likely to expect good intentions from someone they trust as compared to someone who they do not. This was a significant theory for this research; interpersonal trust may be the necessary bridge to reaping the benefits of sarcasm in the workplace without increasing conflict.

Although trust is a necessary factor, business communication can often be indirect and ambiguous. An article from the Journal of Business Ethics stated, "Implicature and indirectness are commonplace in professional communication because they allow speakers and writers to reconcile two opposing goals in discourse, to maneuver between...clarity and politeness" (Riley, 
1993, p.179). Politeness is the filter that keeps communication from being direct and explicit, but when the message is too harsh to seem polite, sarcasm is the vehicle of choice. In such a complex relationship between a supervisor and an employee, careful direction and guidance is important, but there are times in which messages of dissatisfaction must be conveyed. Therefore, not all employees will consistently have only positive experiences with their supervisors, which could lower interpersonal trust between the two. Furthermore, if a negative message must be conveyed early on in the relationship, it could prevent much trust from ever being established. It can be built through activities or events that encourage team building, as team building is seen as a tool that helps to remove emotional barriers to help others function more effectively together (Dirks, 1999).

Carmeli \& Spreitzer further defined trust as "an expression of confidence by a party that his or her vulnerability will not be exploited and that he or she will not be harmed by the behaviors or actions of the other party" $(2009$, p.176). The study further identified trust as a factor in employee thriving due to its ability to encourage employees to actively engage in work and work relationships. The article noted that the psychological stress of mistrust between an employee and their employer can lead to employees spending valuable time and energy on simply navigating the environment around them. If sarcasm between a supervisor and an employee creates mistrust, not only does this damage their relationship, but it could lead to an unproductive and unsuccessful employee. Establishing and maintaining an appropriate level of trust to empower employees is the baseline in a supervisor and employee relationship (George, 2016).

\section{Leader-Member Exchange}


Leader-Member Exchange (LMX) is a leadership theory that focuses on the exchange between a leader and employee and that leaders prefer certain groups over others (George, 2016). "According to LMX, the quality of the relationship that develops between a leader and a follower is predictive of outcomes at the individual, group, and organizational levels of analysis" (Gerstner \& Day, 1997, p.827). The conclusion of Gerstner and Day’s research stated that LMX is consistently linked with member job performance and suggested that the member's perspective more reliably assesses the relationship than the leader's. This highlights the significance of the leader's role in the relationship; a leader is less likely to be aware of discouragement they have caused an employee.

Another study on the mediating role of LMX emphasizes that the exchanges between leaders and each of their followers can vary, meaning that the leader develops different ways of treating each member (Gkorezis, 2015). The study went on to find that employees who have high-quality exchanges with their leaders will exhibit "pro-environmental behavior" and will be more successful in the workplace. A high-quality exchange included words and behaviors that supported subordinates; therefore, sarcasm negatively received would be a low-quality exchange.

Beyond general success, high-quality exchanges between leaders and members can lead to more effective performance appraisals. A study done in fall of 2016 found that employees who have high-quality exchanges with their leaders are more likely to find their performance appraisals fair and to support the criticism of their supervisor (Pichler, et al., 2016). These highquality exchanges increase perception of procedural justice, as employees will view their supervisor's feedback as supportive and valuable for them.

\section{Performance Appraisals}


Deficiencies in performance appraisal implementation have been discussed for decades. The problem often lies in the interpersonal dynamics and the emotional impact on an employee that a poorly conducted performance appraisal can cause (Conant, 1973). However, without performance appraisals, supervisors miss an opportunity to further develop their subordinates (Strother, 2011). Aguinis, et al. define performance management as "a continuous process of identifying, measuring, and developing the performance of individuals and teams and aligning performance with the strategic goals of the organization", and performance appraisal as "the depiction of the strengths and weaknesses of an employee in a non-continuous manner" (2011, p.504). Performance appraisals are an essential part of performance management; where many organizations fail is that they have performance appraisals as their performance management system.

For a performance appraisal to be effective, both supervisor and employee must participate in the process, allowing for employees to take ownership of their performance (Aguinis, Joo, \& Gottfriedson, 2011). The employee relations climate, a phrase referring to the "nature of the social relations between employees and management at any given time", also affects an employee's perception of an appraisal (Haines \& St-Onge, 2012, p.1161). Ironically, there was a significant decline from 2002 to 2012 in upper management involvement in performance appraisals, which stunts the development of employees and the performance management system as a whole (Lawler et. al, 2012). The practice of removing upper management from the performance management system has been found to signal to employees that performance management is unimportant via signalling theory (Biron, Farndale, \& Paauwe, 2011). Signalling theory suggests that the actions of upper management in an organization indirectly convey the values of the organization. For example, an organization who verbally 
states that sustainability is a value but has upper management that makes decisions to not have recycling options in the office actually communicates to employees that sustainability is not a value.

\section{Millennials}

Generation Y, also known as the Millennial generation, is generally defined from around 1980 to 1995, sometimes splitting the younger part into "Generation Z" (Tulgan, 2009). As of now, all Millennials are at an age to be part of the workforce, where they have been causing managerial dysphoria since the late 90s. The managers who have been most successful with managing Millennials in the past have been those who took on the perspective of an internal locus of control, allowing their subordinates to challenge them and work alongside them rather than exerting power over them (Espinoza, et al., 2010). There is something special about Millennials, or so they have been told. Known as the trophy generation, there are some major distinctions between Millennials and their predecessors that have caught some managers off guard. For example, Millennials have been found to not commit to an organization based on job satisfaction, unlike Generation X, Baby Boomers, and the Silent Generation (Stewart, 2016). Millennials are not going to stay with an organization because they are satisfied; they seek adventure and challenge.

Although Millennials seek challenge, they are known for their helicopter parents. This is why Bruce Tulgan suggests the "loco parentis" management, which calls for managers to essentially parent young Millennial employees since that is a staple of Millennial culture (2009). Millennials' deep desire for relationship, coaching, and guidance stems from their closeness with 
their parents, something uncommon in previous generations. Having been told "great job" their entire lives, criticism can be especially difficult for Millennials, making formalities like performance appraisals in the supervisor's office sometimes less effective than a straightforward, in-the-moment confrontation (Espinoza et al., 2010).

Another staple of Millennials is their upbringing in the digital age, with 24 percent of them saying it is what makes their generation distinct, giving them a competitive advantage as a workforce (Stewart, 2016). For Millennials to be most effective as employees, managers must develop ways of communicating with them, via in-person interactions and via technology (Kaifi et. al, 2012). Millennials deeply desire uniqueness and customization, which is often granted to them with today's technology (Tulgan, 2009).

\section{Discussion \& Conclusion}

Since Millennials thrive on close, positive relationships, it would make sense for a supervisor to suggest removing sarcasm from workplace interactions (Tulgan, 2009). However, it is clear that sarcasm is often used regardless of its possible negative side effects and there are also possible benefits to allowing sarcasm in the workplace (Huang, et al., 2015). In terms of this research, the most important aspect is how the presence of sarcasm in a supervisor-employee relationship influences performance appraisal effectiveness; therefore, sarcasm in the workplace in general is not as relevant as sarcasm between an employee and a supervisor. When trust is present, sarcasm between an employee and supervisor can build that relationship, but with risk. Sarcasm recipients are more likely to perceive sarcasm as conflict-provoking when there is mistrust in the relationship, but those who have enough trust can build the relationship (Huang et al., 2015). 
To give an effective performance appraisal, there must be mutual trust between both supervisor and employee (Strother, 2011; Carmeli \& Spreitzer, 2009). Trust is an antecedent to effectiveness and the platform upon which sarcasm benefits can be reaped. If trust is broken and left unrepaired, not only will it be an obstacle in obtaining benefits from sarcasm, but it will also be an obstacle in the performance appraisal process (Carmeli \& Spreitzer, 2009; Lawler et al., 2012). Millennials also thrive from regular feedback, so if trust has been damaged, it could be detrimental beyond the appraisal (They're here! Managing Millennials, 2015). This could be particularly damaging if the supervisor is unaware of the mistrust and continues to use sarcasm with their Millennial subordinate. The damage could make the Millennial employee defensive, unresponsive, and uncommitted, causing their performance to be sub-par, or causing them to leave the organization altogether (Espinoza et al., 2010).

As previously mentioned with LMX, the employee's feelings about the relationship between leader and member are more important than the supervisor's (Gerstner \& Day, 1997). This is exacerbated with sarcasm, as the users of sarcasm typically find more humor in their comments, whereas the victims perceive more aggression (Bowes \& Katz, 2011). Therefore, a supervisor's use of sarcasm with their employee can be dangerous and ambiguous. Perceived aggression leads to prevention orientation and does not allow an employee to engage as easily in creative and critical thinking, again limiting growth opportunities in the appraisal process since employee input is needed (Miron-Spektor et al., 2011; Aguinis, et al., 2011).

Overall, this review shows that there is not substantial research proving that sarcasm between a supervisor and their Millennial employee consistently reduces performance appraisal effectiveness. That being said, with the nature of the Millennial generation, it would be best to err on the side of caution. A supervisor's criticism must be given effectively and received with 
vulnerability for it to be successful. Without the willingness of the employee, the appraisal is rendered useless. There are many contextual complications within each organization and deeper still within supervisor-employee relationships that make distinct do's and don't's difficult to pinpoint. I would suggest based on my research that supervisors refrain from sarcasm between themselves and their Millennial employees, but not necessarily ban it from the workplace as a whole.

By doing so, a manager is more likely to unambiguously build positive relationships with their Millennial employees. Having a positive foundation and a "loco parentis" guiding role toward a Millennial employee will allow them to be more perceptive to constructive criticism, feedback, and progress plans (Tulgan, 2009). That openness should allow supervisors a better opportunity to grow their Millennial employees to their fullest potential and manage their performance most effectively (Espinoza et al., 2010).

\section{Limitations \& Future Research}

There is little current research specifically on sarcasm and Millennials; although one may speculate that sarcasm use has increased and become more commonly used with Generation Y, especially due to internet culture, it remains to be proven. This literature review sought to bring to light intersections of study that have previously been unexplored and call for more research to be focused on the intersections of these topics. The influence of sarcasm on performance appraisals also requires further study. It seems common sense to not use sarcasm in performance appraisal meetings or documentation, but there is more to be discovered about how sarcasm influences it indirectly via the supervisor-employee relationship.

Another limitation is the differences within the Millennial generation that cause them to perceive sarcasm differently, such as gender lines, explored briefly by Bowes and Katz (2011). 
More work could be done on the effects of sarcasm compared between men, women, and other genders. This also applies to the separation of Millennials, noted by Tulgan, of Generation Y and Generation Z (2009). As Generation Z expands to those born in the early 2000s, the full implications of the digital age remain to be seen. Now is the time for research on Generation $\mathrm{Z}$ to be pursued heavily. 


\section{References}

Aguinis, H., Joo, H., Gottfredson, R. K. (2011, November). Why we hate performance management--And why we should love it. Business Horizons, 54(6), 503-507. Retrieved from http://dx.doi.org/10.1016/j.bushor.2011.06.001

Biron, M., Farndale, E., Paauwe, J. (2011, March). Performance management effectiveness: lessons from world-leading firms. The Journal of Human Resource Management, 22(6), 1294-1311. Retrieved from http://dx.doi.org/10.1080/09585192.2011.559100

Boylan, J., Katz, A. N. (2013). Ironic expression can simultaneously enhance and dilute the perception of criticism. Discourse Processes, 50(3), 187-209. http://dx.doi.org/10.1080/0163853X.2012.747041

Bowes, A., Katz, A. (2011). When sarcasm stings. Discourse Processes, 48(4), 215-236. Doi: http://dx.doi.org/10.1080/0163853X.2010.532757

Carmeli, A., Spreitzer, G. M. (2009). Trust, connectivity, and thriving: implications for innovative behavior at work. Journal of Creative Behavior, 43(3), 169-191.

Conant, J. C. (1973, June). The performance appraisal: a critique and an alternative. Business Horizons, 16(3), 73-78.

Dirks, K. T. (1999). The effects of interpersonal trust on work group performance. Journal of Applied Psychology, 84(3), 445-455.

Espinoza, C., Ukleja, M., Rusch, C. (2010). Managing the millennials: discover the core competencies for managing today's workforce. Hoboken, NJ: John Wiley \& Sons.

Fredrickson, B. L., Losada, M. F. (2005, October). Positive affect and the complex dynamics of human flourishing. American Psychologist, 60(7), 678-686. Doi: 10.1037/0003066X.60.7.678 
George, Drake, "Trust \& Growth in the Workplace: An Analysis of Leadership in Flat Organizations" (2016). University Honors Theses. Paper 353. http://pdxscholar.library.pdx.edu/honorstheses/353/

Gerstner, C. R., Day, D. V. (1997). Meta-analytic review of Leader-Member Exchange Theory: correlates and construct issues. The Journal of Applied Psychology, 82(6), 827-844.

Gkorezis, P. (2015). Supervisor support and pro-environmental behavior: the mediating role of LMX. Management Decision, 53(5), 1045-1060. http://dx.doi.org/10.1108/MD-06-2014$\underline{0370}$

Haines III, V. Y., St-Onge, S. (2011, July). Performance management effectiveness: practices or context? The International Journal of Human Resource Management, 23(6), 1158-1175. Retrieved from http://dx.doi.org/10.1080/09585192.2011.561230

Huang, L., Gino, F., Galinksy, A. D. (2015, November). The highest form of intelligence: Sarcasm increases creativity for both expressers and recipients. Organizational Behavior and Human Decision Processes, 131, 162-177. Retrieved from http://dx.doi.org/10.1016/j.obhdp.2015.07.001

Kaifi, B. A., Nafei, W. A., Khanfar, N. M., Kaifi, M. M. (2012, December). A multigenerational workforce: managing and understanding millennials. International Journal of Business and Management 7(24), p.88(6).

Lawler III, E. E., Benson, G. S., McDermott, M. (2012). What makes performance appraisals effective? Compensation and Benefits Review, 44(4), 191-200. Doi: $10.1177 / 0886368712462331$

Leggitt, J. S., Gibbs, R. W. (2000) Emotional reactions to verbal irony. Discourse Processes, 29(1), 1-24. http://dx.doi.org/10.1207/S15326950dp2901_1

Miron-Spektor, E., Efrat-Treister, D., Rafaeli, A., \& Schwarz-Cohen, O. (2011). Others' anger makes people work harder not smarter: The effect of observing anger and sarcasm on creative and analytic thinking. Journal of Applied Psychology, 96(5), 1065-1075. Retrieved from http://stats.lib.pdx.edu/proxy.php?url=http://search.proquest.com/docview/867472721?ac countid=132 
Pexman, P. M., Olineck, K. M. (2002). Does sarcasm always sting? Investigating the impact of ironic insults and ironic compliments. Discourse Processes, 33(3), 199-217. http://dx.doi.org/10.1207/S15326950DP3303_1

Pichler, S., Varma, A., Michel, J. S., Levy, P. E., Budhwar, P. S., Sharma, A. (2016, September/October). Leader-Member Exchange, group- and individual-level procedural justice and reactions to performance appraisals. Human Resources Management, 55(5), 871-883. Doi: 10.1002/hrm.21724

Riley, K. (1993, March). Telling more than the truth: implicature, speech acts, and ethics in professional communication. Journal of Business Ethics, 12(3), 179-196. Retrieved from http://link.springer.com/article/10.1007/BF01686446

Stewart, J. S., Oliver, E. G., Cravens, K. S., Oishi, S. (2016, September). Managing millennials: Embracing generational differences. Business Horizons. Retrieved from http://dx.doi.org/10.1016/j.bushor.2016.08.011

Strother, J. (2011, July/August). Room with review: effective performance appraisals mean never having to say "surprise”. Legal Management, 30(4), 22-29.

They're here! Managing Millennials. (2015, December). Doors and Hardware, 79(12), 36+. Retrieved from http://go.galegroup.com/ps/i.do?p=ITOF\&sw=w\&u=s1185784\&v=2.1\&it=r\&id=GALE \%7CA437224299\&asid=f942d80b3264e774435b7c36c8fc7224

Tulgan, B. (2009). Not Everyone Gets a Trophy: How to Manage Millennials. Hoboken, NJ: Wiley. 